\title{
Targeting Pin 1 Protects Mouse Cardiomyocytes from High-Dose Alcohol-Induced Apoptosis
}

\author{
Yuehong Wang, ${ }^{1}$ Zizhuo Li, ${ }^{2}$ Yu Zhang, ${ }^{3}$ Wei Yang, ${ }^{1}$ Jiantao Sun, \\ Lina Shan, ${ }^{1}$ and Weimin $\mathrm{Li}^{1}$ \\ ${ }^{1}$ Department of Cardiology, The First Affiliated Hospital of Harbin Medical University, Harbin 150001, China \\ ${ }^{2}$ Department of Inpatient Abdominal Ultrasonography, The First Affiliated Hospital of Harbin Medical University, \\ Harbin 150001, China \\ ${ }^{3}$ Department of Neurology, The Fourth Affiliated Hospital of Harbin Medical University, Harbin 150001, China
}

Correspondence should be addressed to Weimin Li; xinxueguan0451@163.com

Received 16 June 2015; Revised 19 August 2015; Accepted 23 August 2015

Academic Editor: Rakesh K. Singh

Copyright (C) 2016 Yuehong Wang et al. This is an open access article distributed under the Creative Commons Attribution License, which permits unrestricted use, distribution, and reproduction in any medium, provided the original work is properly cited.

Long-term heavy alcohol consumption is considered to be one of the main causes of left ventricular dysfunction in alcoholic cardiomyopathy (ACM). As previously suggested, high-dose alcohol induces oxidation stress and apoptosis of cardiomyocytes. However, the underlying mechanisms are yet to be elucidated. In this study, we found that high-dose alcohol treatment stimulated expression and activity of Pinl in mouse primary cardiomyocytes. While siRNA-mediated knockdown of Pinl suppressed alcohol-induced mouse cardiomyocyte apoptosis, overexpression of Pinl further upregulated the numbers of apoptotic mouse cardiomyocytes. We further demonstrated that Pinl promotes mitochondria oxidative stress and loss of mitochondrial membrane potential but suppresses endothelial nitric oxide synthase (eNOS) expression in the presence of alcohol. Taken together, our results revealed a pivotal role of Pinl in regulation of alcohol-induced mouse cardiomyocytes apoptosis by promoting reactive oxygen species (ROS) accumulation and repressing eNOS expression, which could be potential therapeutic targets for ACM.

\section{Introduction}

Heart failure continues to be a major public health issue [1]. In the United States, long-term heavy alcohol consumption is the leading cause of nonischemic dilated cardiomyopathy in both genders, known as "alcoholic cardiomyopathy" (ACM) $[2,3]$. Generally, patients consuming more than $90 \mathrm{~g}$ of alcohol per day for more than 5 years are likely to have asymptomatic $\mathrm{ACM}$, which may develop into symptomatic ACM and signs of heart failure $[2,4]$.

In the asymptomatic stage, ACM is usually characterized by left ventricular dilation, increased left ventricular mass, and reduced or normal left ventricular wall thickness [3, 5]. Pathologically, previous studies have shown a strong correlation between ACM and cardiomyocyte apoptosis [6]. Apoptotic cardiomyocytes were detected in the heart muscles of individuals with long-term alcoholism, and expression of BAX and BCL-2 was also observed $[7,8]$. Studies in animal models also demonstrated that chronic alcohol intake could induce oxidative stress and cellular apoptosis in cardiomyocytes $[9,10]$. In a primary cell culture model, alcohol was found to induce reactive oxygen species-mediated apoptosis in a dose-dependent manner in the range of $0-100 \mathrm{mM}[8$, 11]. However, the molecular mechanism by which alcohol induces apoptosis of cardiomyocytes remains to be investigated.

Peptidyl-prolyl cis-trans isomerase Pinl, a member of the parvulin family of PPIase enzymes, is capable of isomerizing the peptidyl-prolyl bond in specific phosphorylated Ser/ThrPro motifs of the substrates, which may lead to profound changes in their activity, stability, phosphorylation status, and protein-protein interactions $[12,13]$. Pinl was originally found to be required for cell division in yeast and human cells. Later studies demonstrated that Pinl is important for regulation of many other cellular processes, such as gene transcription, cell proliferation, differentiation, and apoptosis 
[14]. In addition, since phosphorylation of proteins is an essential signaling mechanism, Pinl is involved in the Ras signaling pathway and activation of Wnt signaling $[15,16]$.

With regard to regulation of apoptosis, Pinl was found to inhibit apoptosis in hepatocellular carcinoma cells and SW620 cells in colorectal carcinoma $[17,18]$. In this study, we further investigated the role of Pinl in regulation of highdose alcohol-induced cardiomyocyte apoptosis and found that alcohol induced Pinl expression and activation in a dose-dependent manner in primary mouse cardiomyocytes. We further demonstrated that targeting of Pin1 protects cardiomyocytes from high-dose alcohol-induced apoptosis by regulating mitochondria oxidative stress and endothelial nitric oxide synthase (NOS) expression.

\section{Materials and Methods}

2.1. Cell Culture, Cell Transfection, and Reagents. Primary cardiomyocytes were isolated from neonatal mouse hearts, as described previously [19]. Briefly, heart tissue was minced and digested, using a collagenase/dispase mixture (Roche, Indianapolis, IN). Tissue fragments were allowed to sediment, and the supernatant-containing suspended cells were preplated for $2 \mathrm{~h}$ to remove fibroblasts and endothelial cells. Enriched cardiomyocytes were then cultured in collagencoated dishes at approximately $1.5 \times 10^{5}$ cells per $\mathrm{cm}^{2}$. All animal procedures were conducted in accordance with the Guidelines for the Care and Use of Laboratory Animals at Harbin Medical University and approved by the Chancellor's Animal Research Committee.

Scrambled and Pinl siRNAs were purchased from Invitrogen (Carlsbad, CA) and transfected with Lipofectamine RNAiMAX (Invitrogen). Pinl plasmids were obtained from Addgene (Cambridge, MA). Lipofectamine LTX (Invitrogen) was used for plasmid transfection according to the manufacturer's instructions. Cardiomyocytes $\left(5 \times 10^{4}\right.$ cells/well $)$ were seeded onto 24-well plates and grown overnight to approximately $80 \%$ confluence. The cells were transfected with 30 pmol siRNA or $500 \mathrm{ng}$ plasmid and incubated for $48 \mathrm{~h}$, and subsequent experiments were performed after transfection to analyze efficiency, using western blotting.

$\mathrm{N}$-acetylcysteine (NAC) and Mito-TEMPO were purchased from Sigma-Aldrich (St. Louis, MO, USA).

\subsection{Quantitative Reverse Transcription Polymerase Chain} Reaction ( $q R T-P C R)$. Total RNA was extracted from cardiomyocytes, using the TRIzol reagent (Life Technologies, Gaithersburg, MD) according to the manufacturer's instructions, and complementary DNA was then synthesized from $1 \mu \mathrm{g}$ of total RNA from each sample, using the SuperScript III First-Strand Synthesis System (Life Technologies). mRNA expression levels of Pin1 were measured by qRT-PCR and calculated using the $2^{-\Delta \Delta \mathrm{Ct}}$ method and normalized to the expression of glyceraldehyde 3-phosphate dehydrogenase (GAPDH). The primers of oligonucleotides were as follows:

5'-CCGGAATTCATGGCGGACGAGGAGAAG-3' (forward) and

\author{
5'-TGCTCTAGATCATTCTGTGCGCAGGAT-3' \\ (reverse) for Pinl; \\ $5^{\prime}$-TGGACTCCACGACGTACTCAG-3' (forward) \\ and $5^{\prime}$-GGGAAGCTTGTCATCAATGGAA- ${ }^{\prime}$ \\ (reverse) for GAPDH.
}

2.3. Western Blotting. Cardiomyocytes were harvested and lysed on ice for $30 \mathrm{~min}$ in RIPA buffer $(120 \mathrm{mM} \mathrm{NaCl}, 40 \mathrm{mM}$ Tris [ $\mathrm{pH}$ 8.0], and $0.1 \% \mathrm{NP} 40$ ) with proteinase/phosphatase inhibitor (Pierce, Rockford, IL). The lysates were centrifuged at $18,000 \mathrm{~g}$ for $15 \mathrm{~min}$ at $4^{\circ} \mathrm{C}$. The supernatants were collected, and protein concentrations were determined by the BCA method (Pierce). Aliquots of the lysates were electrophoresed on a $10 \%$ sodium dodecyl sulfate-polyacrylamide gel (SDSPAGE). The resolved protein was then transferred onto nitrocellulose membranes (Bio-Rad, Hercules, CA), which were subsequently incubated with primary antibodies, followed by a horseradish peroxidase-conjugated secondary antibody (Boster, Wuhan, China). Protein bands were detected using an enhanced chemiluminescence western blotting detection kit (Pierce), followed by exposure of the membranes to Xray film. Primary antibodies for Pinl, cytochrome c (Cyt.C), endothelial nitric oxide synthase (eNOS), mHsp70, p66 ${ }^{\text {shc }}$, and $\beta$-actin were purchased from Santa Cruz (Santa Cruz, CA).

2.4. Pin1 Activity Assays. Pinl activity was analyzed as previously described [20, 21]. Briefly, cardiomyocytes were lysed by sonication in lysis buffer $(50 \mathrm{mM} \mathrm{N}-2$ hydroxyethylpiperazine- $\mathrm{N}^{\prime}$-2-ethanesulfonic acid, $100 \mathrm{mM}$ $\mathrm{NaCl}, \quad 0.25 \%$ 3-[(3-cholamidopropyl) dimethylammonio]1-propanesulfonate (CHAPS), $5 \mathrm{mM} \quad \mathrm{NaF}, 1 \mathrm{mM} \quad \beta$ glycerophosphate, and $1 \mathrm{mM}$ ethylene glycol tetraacetic acid) at $4^{\circ} \mathrm{C}$. We then prepared a mixture containing $93 \mu \mathrm{L}$ of $\mathrm{N}$-2-hydroxyethylpiperazine- $\mathrm{N}^{\prime}$-2-ethanesulfonic acid buffer $\left(50 \mathrm{mM} \quad \mathrm{N}\right.$-2-hydroxyethylpiperazine- $\mathrm{N}^{\prime}$-2ethanesulfonic acid ( $\mathrm{pH} 7.8), 100 \mathrm{mM} \mathrm{NaCl}, 2 \mathrm{mM}$ DTT, $0.04 \mathrm{mg} / \mathrm{mL}$ of bovine serum albumin $), 5 \mu \mathrm{L}$ of cell lysate $\left(10^{5}\right.$ cells or $0.25 \mathrm{nmol}$ of recombinant Pinl), and $2 \mu \mathrm{L}(20 \mathrm{mg} / \mathrm{mL})$ of trypsin solution. The reaction was started by adding $50 \mu \mathrm{L}$ $(720 \mu \mathrm{M})$ of peptide Trp-Phe-Tyr-Ser $\left(\mathrm{PO}_{3} \mathrm{H}_{2}\right)$-ProArg-pNA (NeoMPS), followed by $p$-nitroaniline absorbance at $390 \mathrm{~nm}$ for $4 \mathrm{~min}$.

2.5. Cell Viability Assays. Cardiomyocyte viability was measured using a 3-(4,5-dimethylthiazol-2-yl)-2,5-diphenyltetrazolium bromide (MTT) assay. Cells were plated at $3 \times 10^{3}$ cells per well in $100 \mu \mathrm{L}$ culture medium in 96-well culture plates. Sterile MTT dye $(20 \mu \mathrm{L})$ (Sigma) was added to each well. After incubating for $4 \mathrm{~h}$ at $37^{\circ} \mathrm{C}$, MTT medium mixture was removed, and $200 \mu \mathrm{L}$ of dimethyl sulfoxide (Sigma) was added to each well. The absorbance representing viable cells was measured by a microplate reader at a wavelength of $490 \mathrm{~nm}$. Cell viability was calculated as a relative ratio of the control.

2.6. Caspase Activity Assays. Cells $\left(1 \times 10^{4}\right)$ were incubated in 96-well plates for $24 \mathrm{~h}$, and caspase- 3 activity was measured 
using the caspase- 3 and caspase- 9 assay kits (Ambion, Austin, TX) according to the manufacturer's protocol. Briefly, the cells were incubated with lysis buffer on ice for $10 \mathrm{~min}$ and collected via 10,000 g centrifugation for $10 \mathrm{~min}$. Protein $(100 \mu \mathrm{g})$ from each sample was incubated with specific colorimetric tetrapeptides Asp-Glu-Val-Asp-p-nitroaniline (pNA; specific substrate of caspase-3) or Leu-Glu-His-Asp-pNA (specific substrate of caspase-9) at $37^{\circ} \mathrm{C}$ for $60 \mathrm{~min}$. The activity of caspase- 3 and caspase- 9 was quantified using a spectrophotometer at $405 \mathrm{~nm}$, and the data were normalized to the control group.

2.7. TUNEL Staining. TUNEL staining was performed using the DeadEnd Fluorometric TUNEL System (Promega, Madison, WI) according to the manufacturer's protocol. Briefly, cells were grown on chambered culture slides, fixed with $4 \%$ PFA for $2 \mathrm{~h}$ at room temperature, and permeabilized with $0.2 \%$ Triton X-100 in PBS for 5 min. Cells were washed again with PBS and equilibrated with $100 \mu \mathrm{L}$ equilibration buffer at room temperature for $10 \mathrm{~min}$. Slides were covered with $50 \mu \mathrm{L}$ of terminal deoxynucleotidyl transferase reaction mixture for $60 \mathrm{~min}$ in a humidified chamber. The reaction was stopped with $2 \mathrm{x}$ SSC for $15 \mathrm{~min}$. Nuclei were visualized by DAPI staining.

2.8. Mitochondrial Membrane Potential Measurements. Mitochondrial membrane potential $(\Delta \psi \mathrm{m})$ was assessed using a TMRE Mitochondrial Membrane Potential Assay Kit (Abcam, Cambridge, England). Cells were incubated with $100 \mathrm{nM}$ TMRE in the absence or presence of CCCP at $20 \mu \mathrm{M}$ at $37^{\circ} \mathrm{C}$ for $15 \mathrm{~min}$ and washed with $0.2 \%$ BSA in PBS. The cell pellet was collected by centrifugation at $1500 \mathrm{~g}$ for $3 \mathrm{~min}$ and resuspended in $1 \mathrm{~mL}$ of PBS. Fluorescence was measured by a fluorescence plate reader (BioTek, Burlington, VT).

2.9. Measurement of Cyt.C Release from Mitochondria to Cytosol. Release of Cyt.C from mitochondria to cytosol was measured by western blotting, as previously described [22]. Cells $\left(5 \times 10^{6}\right)$ were collected by trypsin-EDTA $(0.5 \%)$, followed by two washes with cold PBS and lysed in ice-cold lysis buffer (250 mM sucrose, $1 \mathrm{mM}$ EDTA, 0.05\% digitonin, $25 \mathrm{mM}$ Tris ( $\mathrm{pH}$ 6.8), $1 \mathrm{mM}$ dithiothreitol, $1 \mu \mathrm{g} / \mathrm{mL}$ leupeptin, $1 \mu \mathrm{g} / \mathrm{mL}$ pepstatin, $1 \mu \mathrm{g} / \mathrm{mL}$ aprotinin, $1 \mathrm{mM}$ benzamidine, and $0.1 \mathrm{mM}$ phenylmethylsulfonyl fluoride). Lysates were centrifuged at $12,000 \mathrm{~g}$ at $4^{\circ} \mathrm{C}$ for $3 \mathrm{~min}$ to obtain the supernatants for western blot analysis. Protein concentration in the supernatants was measured using BCA protein assay kit (Thermo Fisher Scientific, Canoga Park, CA).

2.10. Measurement of NO Production and Mitochondrial ROS. Nitric oxide production was assessed by measuring the levels of oxidized forms (nitrites and nitrates) in samples, using a nitric oxide assay kit (Abcam, Cambridge, UK). Mitochondrial ROS levels were analyzed using the Elite Mitochondrial ROS Activity Assay Kit (eEnzyme, Gaithersburg, MD). Cells were harvested and incubated with $100 \mu \mathrm{L}$ Elite ROS Deep Red stain solution on 96-well plates for $60 \mathrm{~min}$ at $37^{\circ} \mathrm{C}$. Fluorescence intensity was measured at EX/EM = $650 / 675 \mathrm{~nm}$.

2.11. Mitochondrial Protein Isolation. Cells were centrifuged at $370 \mathrm{~g}$ for $10 \mathrm{~min}$ and washed in 10 packed cell volumes of washing buffer $(1 \mathrm{mM}$ Tris $\mathrm{HCl}, \mathrm{pH} 7.4,0.13 \mathrm{M} \mathrm{NaCl}$, $5 \mathrm{mM} \mathrm{KCl}$, and $7.5 \mathrm{mM} \mathrm{MgCl}_{2}$ ) three times. Cells were then resuspended in 6 packed cell volumes of homogenization buffer (10 mM Tris $\mathrm{HCl}$, pH 7.4, $10 \mathrm{mM} \mathrm{KCl,} 0.15 \mathrm{mM} \mathrm{MgCl}$, $1 \mathrm{mM}$ PMSF, and $1 \mathrm{mM}$ DTT) and homogenized for $10 \mathrm{~min}$ on ice. Homogenate was transferred into a conical centrifuge tube containing 1 packed cell volume of $2 \mathrm{M}$ sucrose solution. Unbroken cells, nuclei, and large debris were removed by centrifuging at $1,200 \mathrm{~g}$ for $5 \mathrm{~min}$ twice. The mitochondria were collected by centrifuging at 7,000 $\mathrm{g}$ for $10 \mathrm{~min}$. The mitochondrial pellet was resuspended in 3 packed cell volumes of mitochondrial suspension buffer $(10 \mathrm{mM}$ Tris $\mathrm{HCl}, \mathrm{pH}$ 6.7, $0.15 \mathrm{mM} \mathrm{MgCl}_{2}, 0.25 \mathrm{mM}$ sucrose, $1 \mathrm{mM}$ PMSF, and $1 \mathrm{mM}$ DTT) for further western blot analysis.

2.12. Statistical Analyses. All statistical analyses were performed using SPSS 18.0 software (IBM, Chicago, IL). The significance of differences between groups was estimated by Student's $t$-test, $\chi^{2}$ test, or one-way analysis of variance (ANOVA). The data were expressed as the mean \pm SEM of three independent experiments. A $p$ value of 0.05 or less was considered to be statistically significant.

\section{Results}

3.1. Alcohol Induced Pin1 Expression and Activation in Cardiomyocytes. We had previously demonstrated that high doses of alcohol induce cardiomyocyte apoptosis [11]. To investigate whether Pinl plays a role in alcohol-induced apoptosis in cardiomyocytes, we first analyzed Pin1 expression after exposing cells to different concentrations of alcohol (ethanol: 0, 50, 100, or $200 \mathrm{mM}$ ). As shown in Figures 1(a) and 1(b), alcohol caused dose-dependent upregulation of Pin1 expression at both the mRNA and protein levels. Moreover, alcohol increased Pinl activity in a dose-dependent manner (Figure 1(c)).

3.2. Pin1 Regulated Alcohol-Induced Apoptosis in Cardiomyocytes. We investigated whether Pinl is involved in alcoholinduced cardiomyocyte apoptosis by both loss- and gain-offunction studies. We first transfected mouse cardiomyocytes with control or Pin1 siRNA for $24 \mathrm{~h}$ and exposed those cells to alcohol $(200 \mathrm{mM})$ for another $24 \mathrm{~h}$. Knockdown efficiency was confirmed by western blotting (Figure 2(a)). As expected, cell viability decreased by more than $50 \%$ in the alcoholtreated group as compared to cells in the control group. However, the viability of Pinl-knockdown cells only decreased by $20 \%$ with alcohol treatment (Figure 2(b)). Caspase- 9 and caspase- 3 activity assays and TUNEL staining consistently showed that alcohol-induced cell apoptosis was inhibited by depletion of Pin1 (Figures 2(c) and 2(d)). Interestingly, ectopic overexpression of Pinl further enhanced alcoholinduced apoptosis and loss of cell viability (Figures 3(a)$3(d))$. Together these results indicate that Pinl plays an 


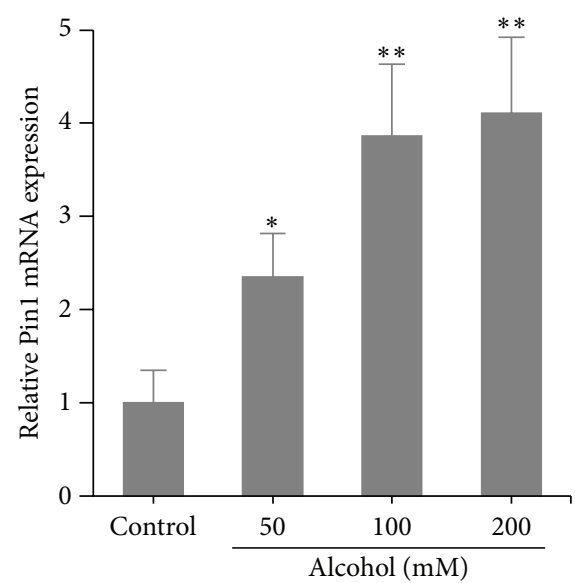

(a)

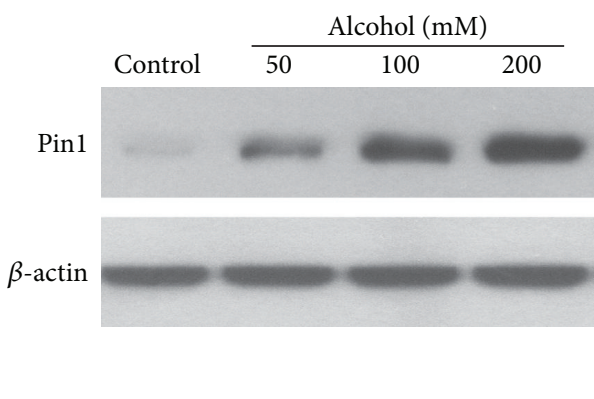

(b)

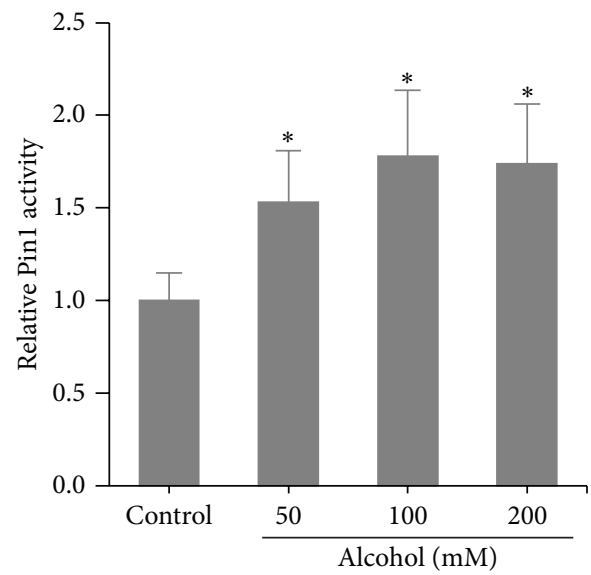

(c)

FIGURE 1: Pinl expression and activity were upregulated by alcohol treatment of cardiomyocytes. (a) qRT-PCR of Pinl mRNA expression in cardiomyocytes treated with alcohol $(0,50,100$, or $200 \mathrm{mM})$ for $24 \mathrm{~h}$. (b) Western blot of Pinl expression in cardiomyocytes treated with alcohol at indicated concentrations. (c) Pinl activity assays in cardiomyocytes treated with alcohol at indicated concentrations. ${ }^{*} p<0.05$ and ${ }^{* *} p<0.01$ compared to cells without alcohol treatment.

important role in promoting alcohol-induced apoptosis in cardiomyocytes.

\subsection{Knockdown of Pin1 Reduced Alcohol-Mediated Mito-} chondria Oxidative Stress in Cardiomyocytes. Mitochondrial oxidative signaling contributes to alcohol-induced apoptosis [11], and downregulation of Pinl can prevent mitochondrial oxidative stress in patients with diabetes [23]. Thus, we investigated whether depletion of Pin1 can prevent alcohol-induced mitochondrial oxidative stress in cardiomyocytes. mCyt.C, mitochondrial membrane potential, and mitochondrial reactive oxygen species (mROS) were examined in control and Pinl-knockdown cardiomyocytes in the presence or absence of $200 \mathrm{mM}$ alcohol. Downregulation of Pinl significantly reversed mCyt.C release, reduced mitochondrial membrane potential, and stimulated mROS production induced by alcohol treatment (Figures 4(a)$4(\mathrm{c})$ ). We next sought to recapitulate the result by using Pin1 inhibitor Juglone. Unlike Pin1 knockdown cells, cells treated with Pinl inhibitor Juglone $(2.5 \mu \mathrm{M})$ demonstrated lower cell viability and higher apoptosis in both condition without or with alcohol treatment (Supplemental Figure 1; see Supplementary Materials available online at http://dx.doi.org/10.1155/2016/4528906). Since Pin1 has been reported to be a strong cytotoxic agent and induce apoptosis in many cell types $[24,25]$, the apoptosis-inducing activity of Juglone in cardiomyocytes might be through other signaling pathways than inhibiting Pin1. We next overexpressed Pin1 in cardiomyocytes. As expected, alcohol induced mCyt.C release, mitochondrial membrane potential reduction, and ROS production, which were further enhanced by Pin1 overexpression (Figures 4(d)-4(f)). In addition, we tested whether scavenging of ROC could reverse cell viability and apoptosis in alcohol-treated cardiomyocytes. As showed in Figures 4(g) and 4(h), two ROS scavengers (NAC and Mito-TEMPO) all partly rescued alcohol-induced cell death and apoptosis in Pinl-overexpressed cardiomyocytes. Our previous work has found that Pinl interacts with p-p66Shc which translocates to mitochondria and functions as a redox enzyme to regulate cardiomyocyte apoptosis [11]. To further 


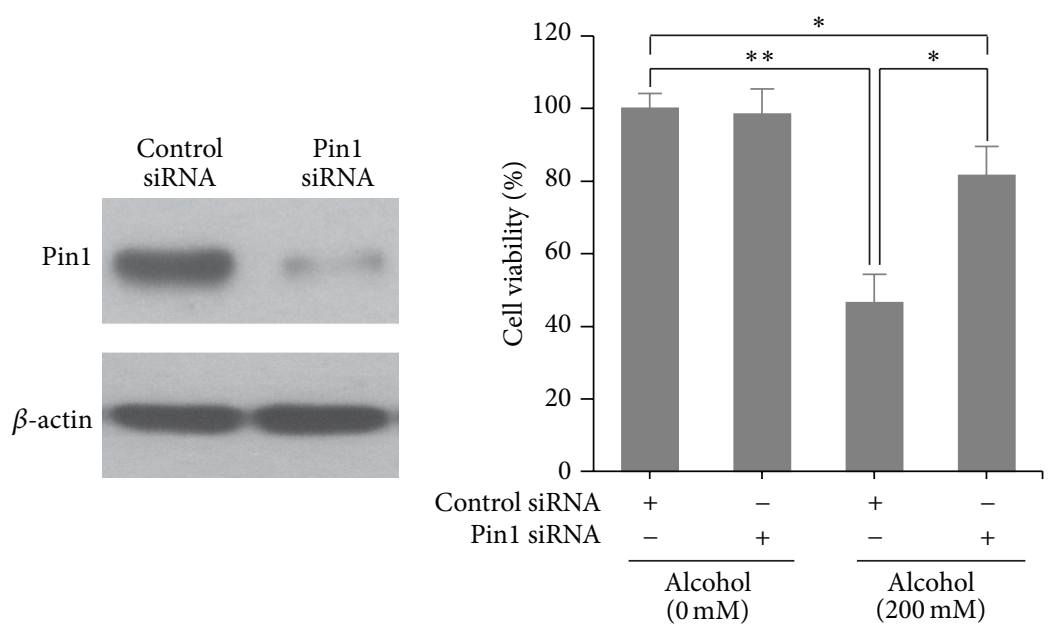

(a)

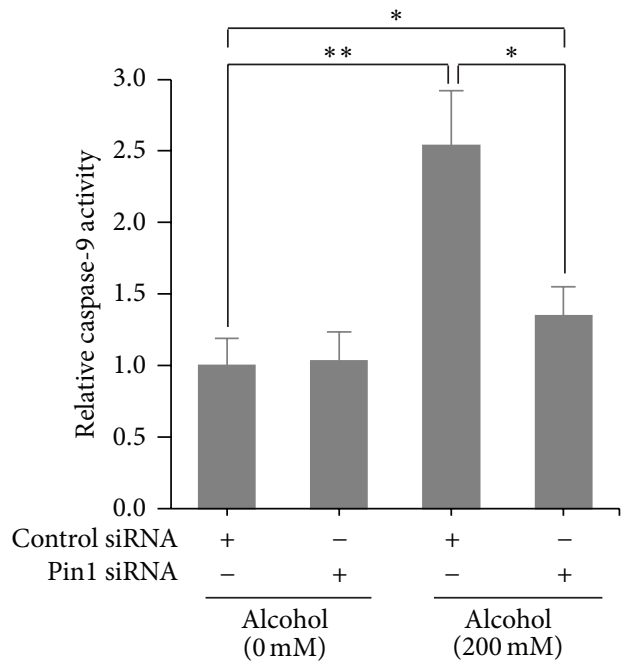

(b)

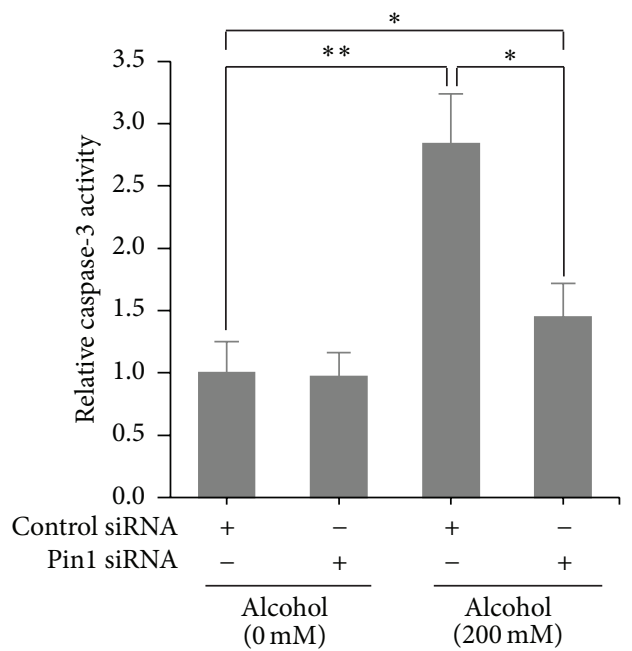

(c)
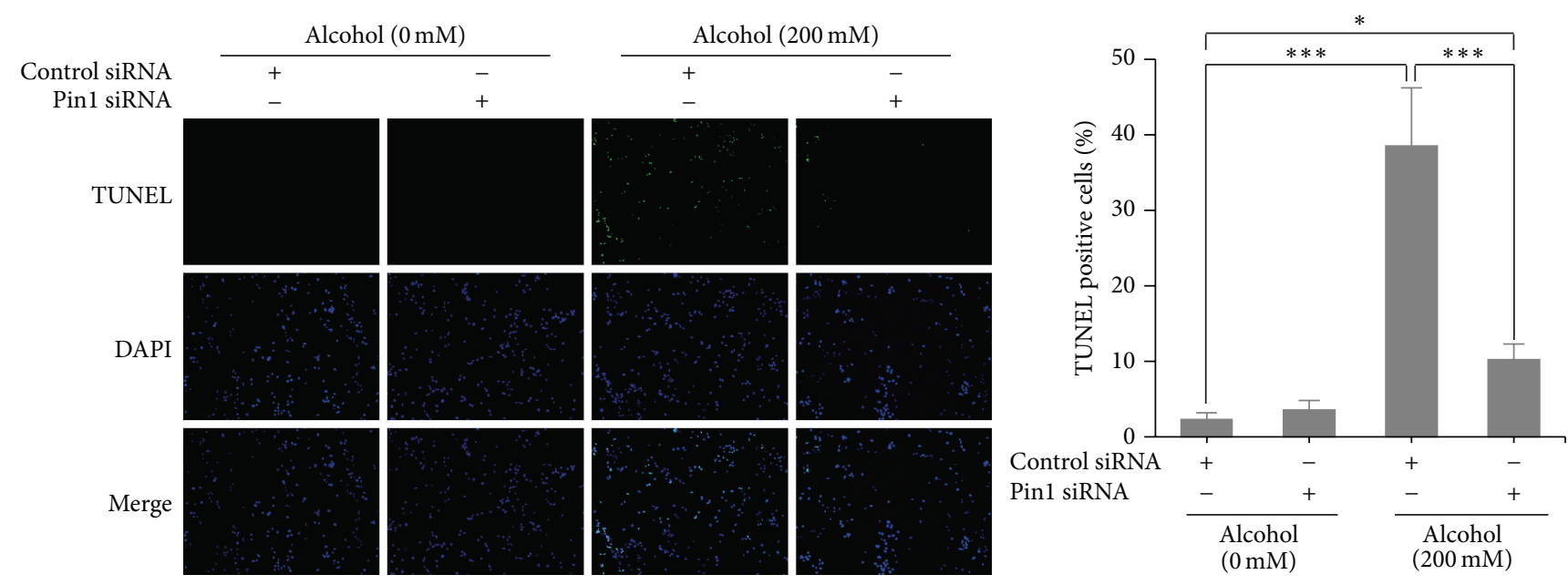

(d)

FIGURE 2: Knockdown of Pinl inhibited alcohol-induced cardiomyocyte apoptosis. (a) Pinl protein expression measured by western blotting after Pin1 siRNA transfection. ((b)-(d)) Cell viability assay (b), caspase-9 and caspase-3 activity assays (c), and TUNEL staining (d) in Pin1knockdown cardiomyocytes treated or untreated with alcohol $(200 \mathrm{mM})$ for 24 h. ${ }^{*} p<0.05,{ }^{* *} p<0.01$, and ${ }^{* * *} p<0.001$. 


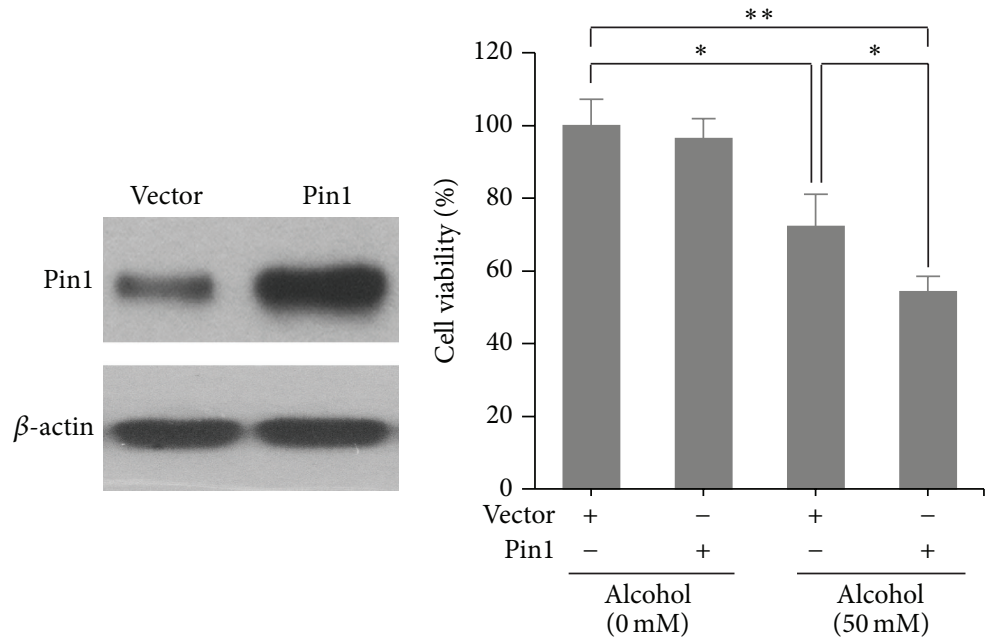

(a)

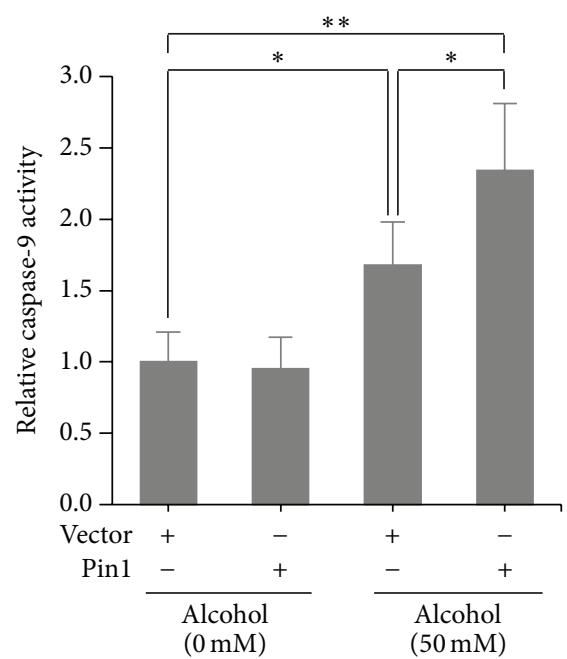

(b)

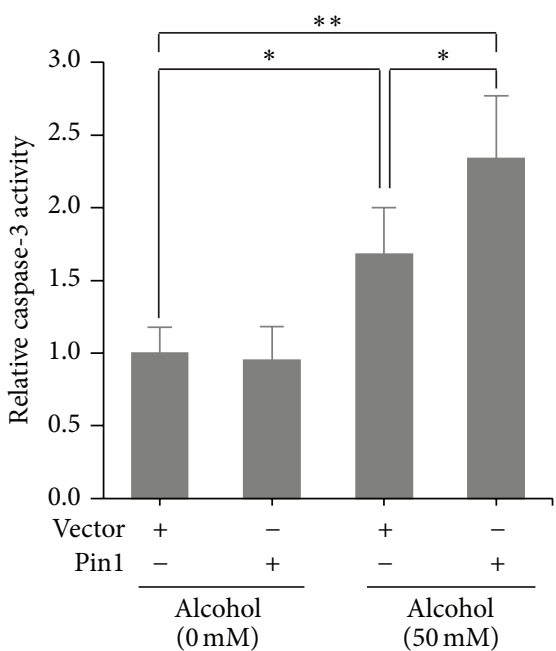

(c)
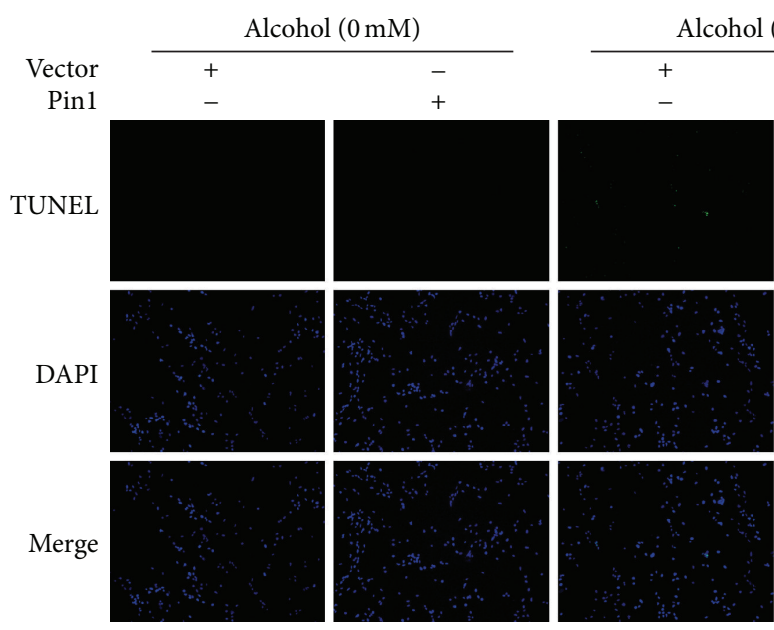

$50 \mathrm{mM})$
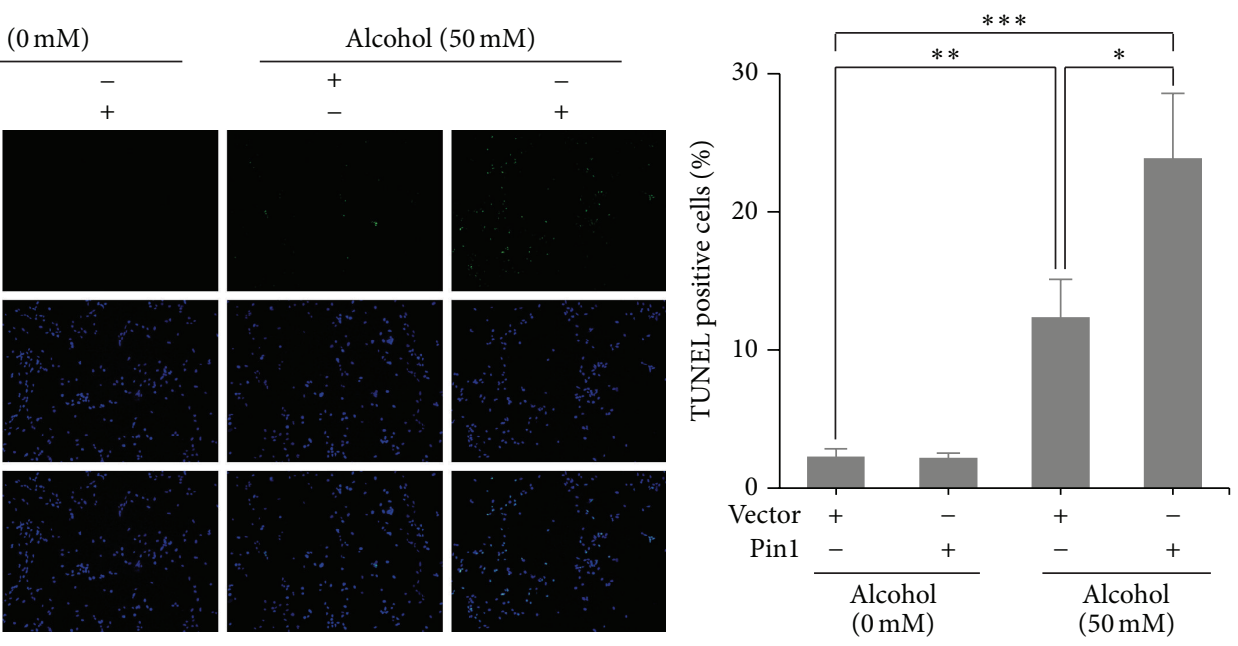

(d)

Figure 3: Overexpression of Pinl enhanced alcohol-induced cardiomyocyte apoptosis. (a) Pin1 protein expression measured by western blotting after Pin1 plasmid transfection. Cell ability (b), caspase-9 and caspase-3 activity assay (c), and TUNEL staining (d) in Pin1overexpressed cardiomyocytes treated or untreated with alcohol $(50 \mathrm{mM})$ for $24 \mathrm{~h} .{ }^{*} p<0.05,{ }^{* *} p<0.01$, and ${ }^{* * *} p<0.001$. 


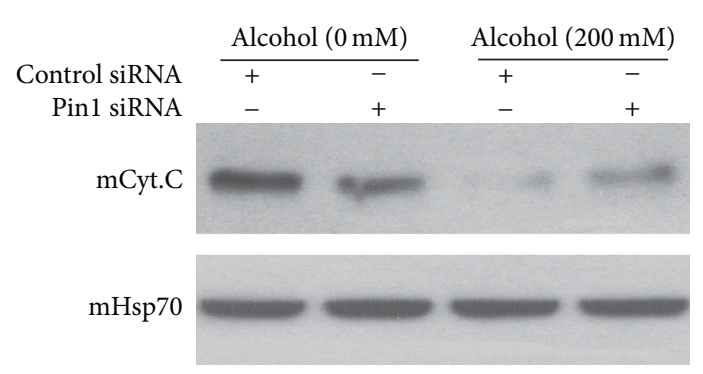

(a)

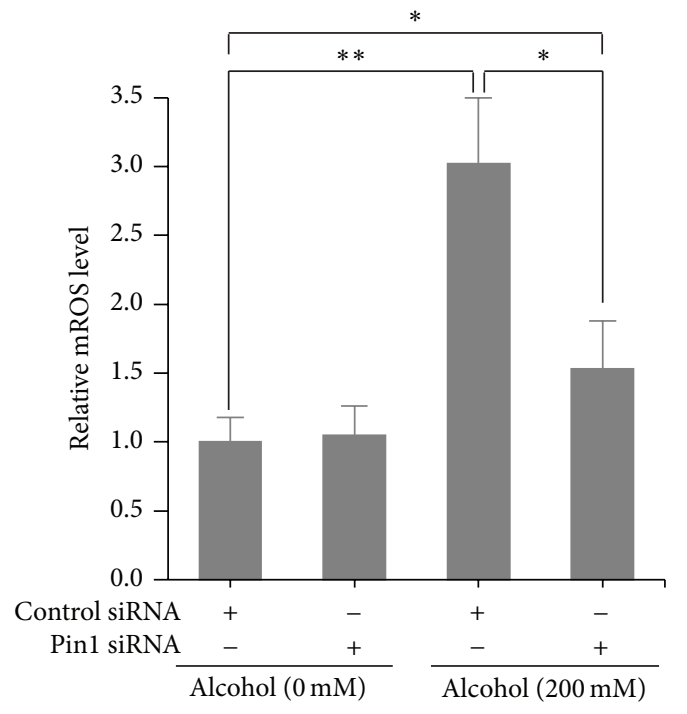

(c)

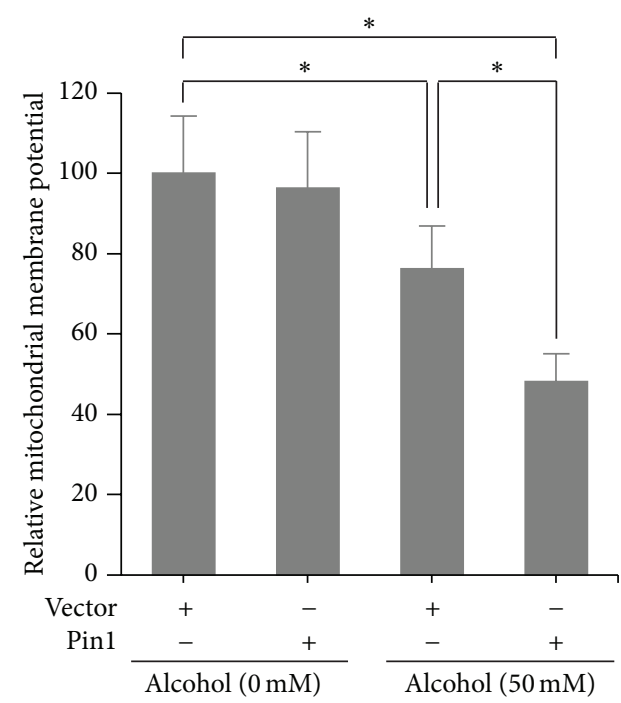

(e)

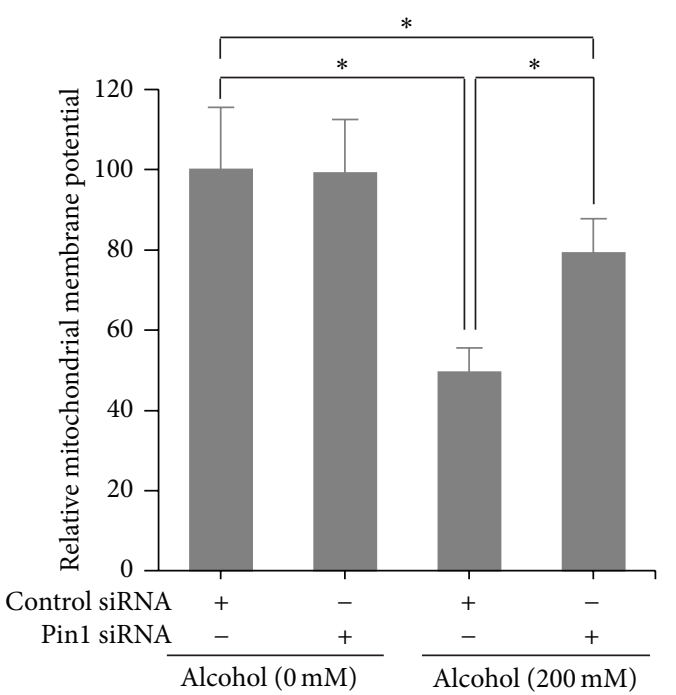

(b)

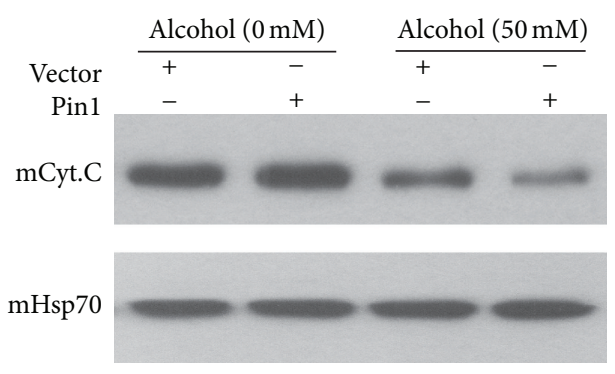

(d)

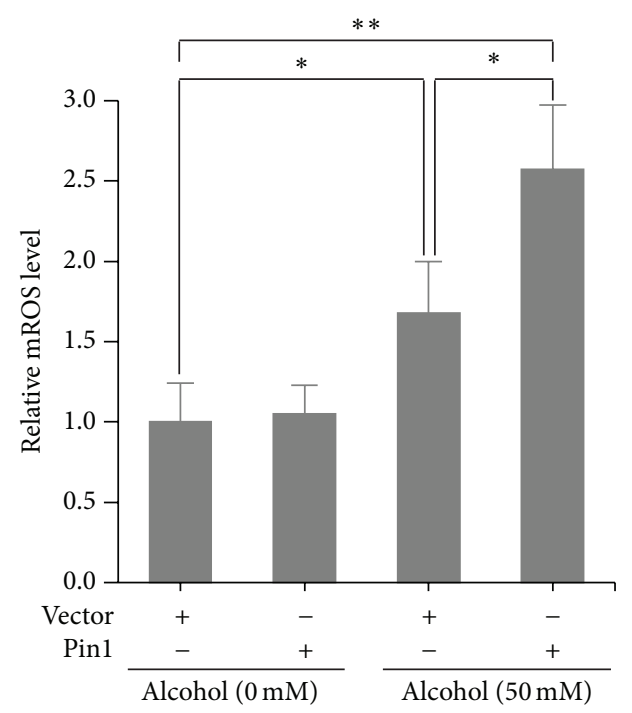

(f)

FIGURE 4: Continued. 


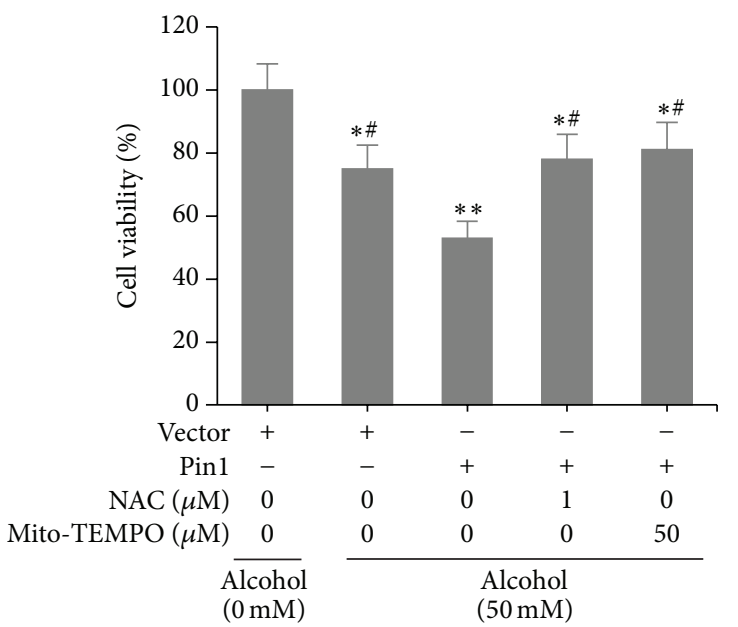

(g)

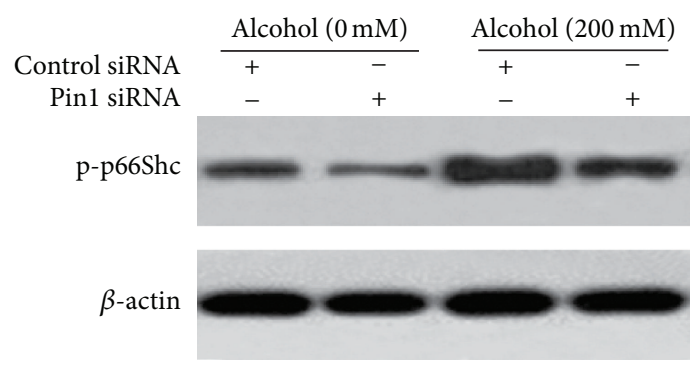

(i)

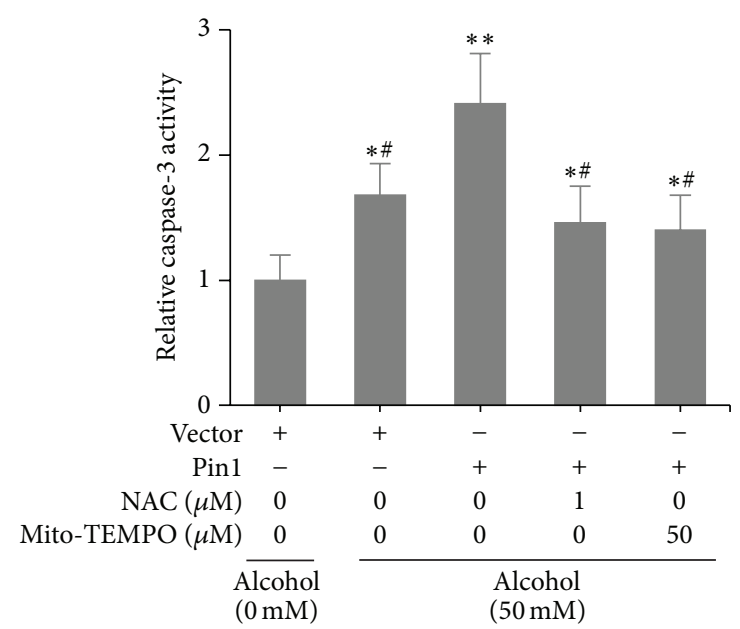

(h)

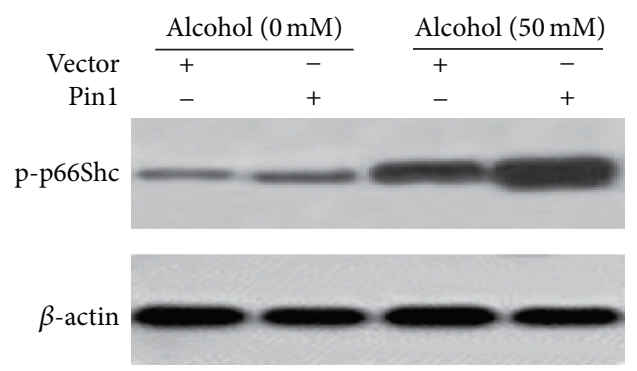

(j)

FIGURE 4: Pinl enhanced alcohol-mediated mitochondria oxidative stress in cardiomyocytes. (a) Western blot of mCyt.C release in Pin1knockdown cardiomyocytes treated or untreated with alcohol $(200 \mathrm{mM})$ for $24 \mathrm{~h}$. Relative mitochondrial membrane potential (b) and $\mathrm{mROS}$ levels (c) in cells are indicated. (d) mCyt.C levels in Pinl-overexpressed cardiomyocytes treated or untreated with alcohol (50 mM) for $24 \mathrm{~h}$. Relative mitochondrial membrane potential (e) and mROS levels (f) in cells are indicated. ${ }^{*} p<0.05$ and ${ }^{* *} p<0.01$. Cell viability (g) and caspase- 3 activity (h) assays in Pinl-overexpressed cells treated with alcohol $(50 \mathrm{mM})$ and NAC $(1 \mu \mathrm{M})$ or Mito-TEMPO $(50 \mu \mathrm{M}) .{ }^{*} p<0.05$ and ${ }^{* *} p<0.01$ compared with cells untreated with alcohol; ${ }^{*} p<0.05$ compared with Pinl overexpression cells treated with alcohol only. (i) Western blot of mitochondrial p-p66Shc levels in control or Pinl-knockdown cardiomyocytes treated or untreated with alcohol (200 mM) for $24 \mathrm{~h}$. (j) Western blot of mitochondrial p-p66Shc levels in Pinl-overexpressed cardiomyocytes treated or untreated with alcohol (50 mM) for $24 \mathrm{~h}$.

investigate the downstream signaling of Pinl in alcoholinduced cardiomyocyte apoptosis, we analyzed the mitochondrial p-p66Shc levels in cardiomyocytes treated with or untreated with alcohol in Pinl knockdown or overexpression cells. As we expected, knockdown of Pinl reduced and overexpression of Pin increased mitochondrial p-p66Shc level (Figures 4(i) and 4(j)). Taken together, this demonstrates that Pinl promotes alcohol-mediated mitochondria oxidative stress in cardiomyocytes.

\subsection{Pin1 Regulated Alcohol-Mediated NO Production and} eNOS Expression in Cardiomyocytes. Since nitric oxide (NO) plays a role in apoptosis of cardiomyocytes [24], we investigated whether alcohol mediates endothelial eNOS expression. As shown in Figures 5(a)-5(c), alcohol inhibited NO production and eNOS levels in a dose-dependent manner. We also tested alcohol-induced NO production and eNOS expression in Pinl-knockdown cells. Compared to control cells, alcohol significantly decreased NO production, while knockdown of Pinl partly reversed its decrease of production
(Figure 5(c)). eNOS expression was consistently rescued by Pinl depletion in the presence of alcohol (Figure 5(d)). To further confirm Pinl function in alcohol-mediated NO production and eNOS expression, we overexpressed Pin1 in cardiomyocytes and assessed NO and eNOS levels after alcohol $(50 \mathrm{mM})$ treatment. As shown in Figures 5(e) and 5(f), overexpression of Pinl further inhibited NO production and eNOS expression, which demonstrates that Pinl regulates alcohol-mediated NO production by affecting eNOS expression in cardiomyocytes.

\section{Discussion}

Apoptosis is a mechanism of programmed cell death implicated in the pathogenesis of alcohol-induced left ventricular dysfunction [1]. Several mechanisms have been proposed to explain the role of alcohol during development of ACM, such as upregulated ROS levels and decreased NO production $[11,25,26]$. In this study, we found that alcohol elevated Pin1 expression and activity in mouse primary cardiomyocytes. 

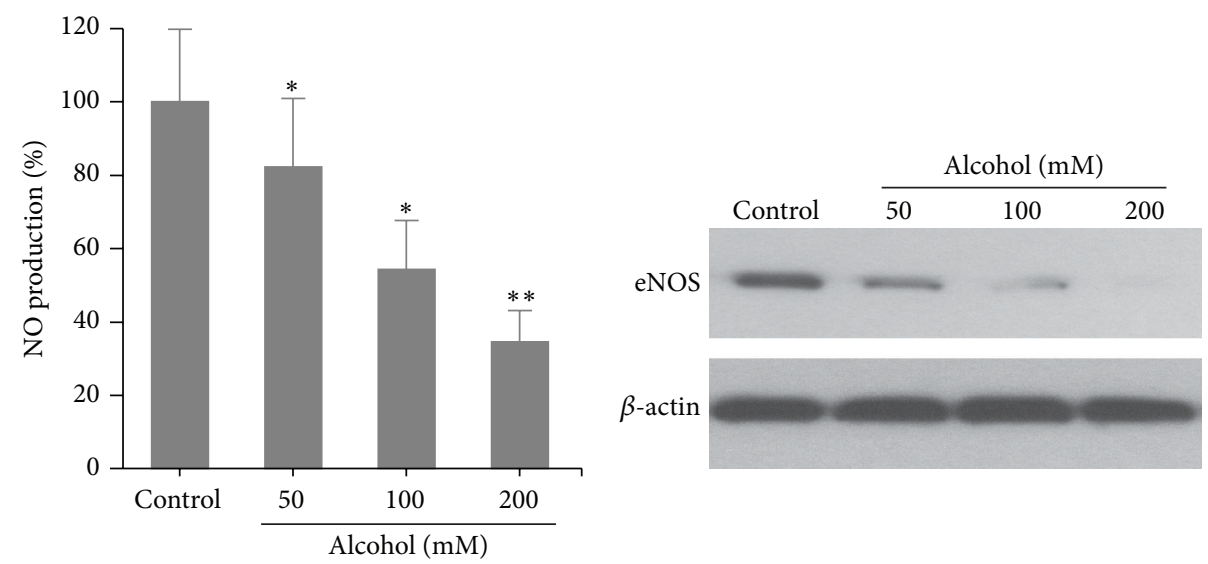

(a)

(b)
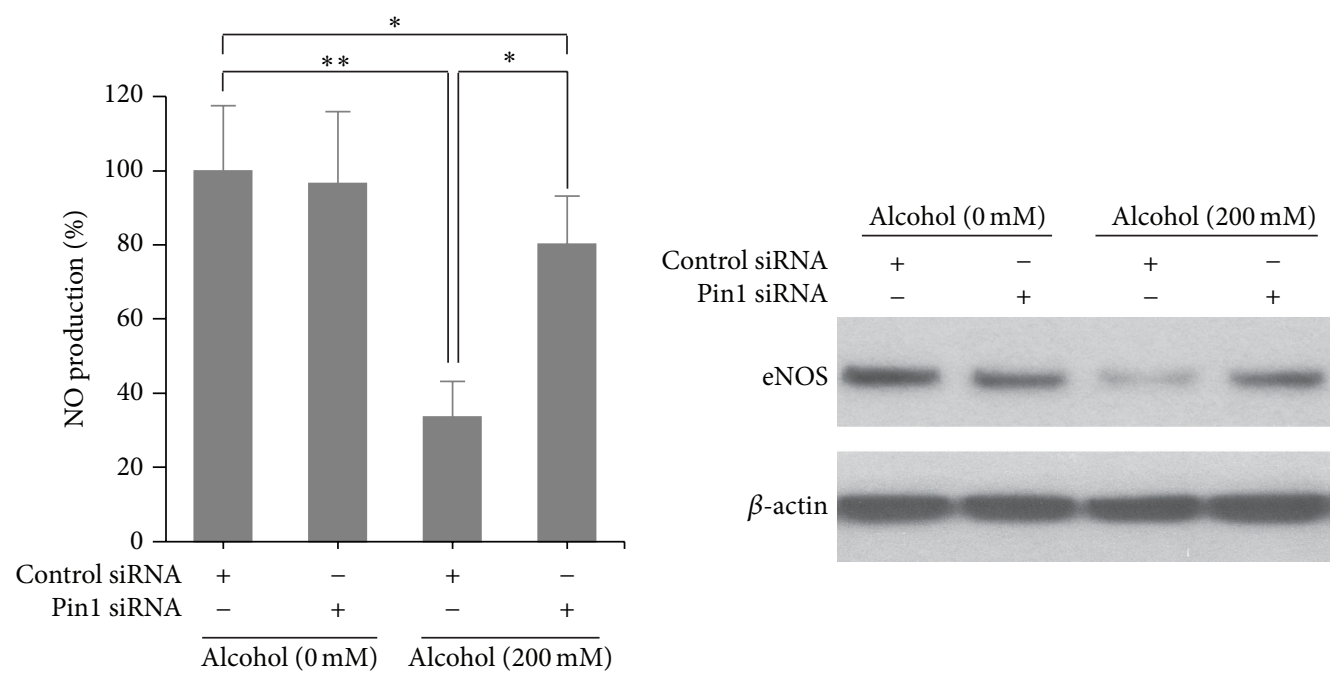

(c)

(d)
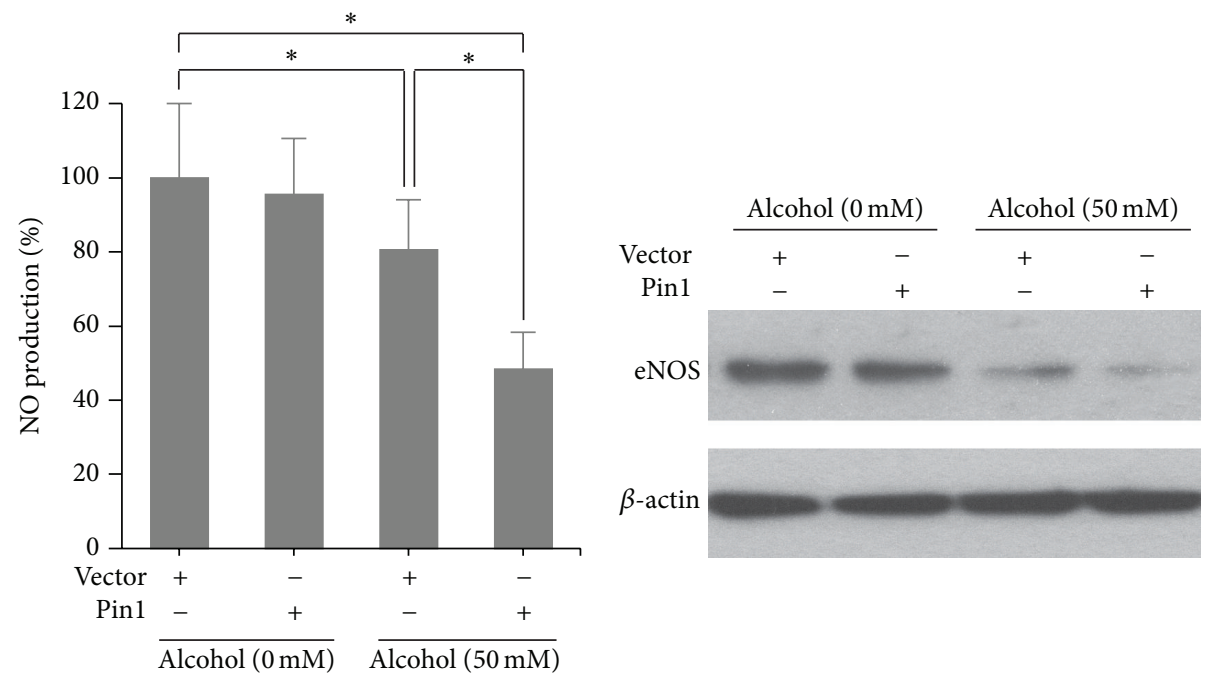

(e)

(f)

FIGURE 5: Pinl reduced the NO production and eNOS expression that were inhibited by alcohol in cardiomyocytes. (a) NO production in cardiomyocytes treated with alcohol $(0,50,100$, or $200 \mathrm{mM})$ for $24 \mathrm{~h}$. (b) eNOS expression analyzed by western blotting in cells treated with alcohol at indicated concentrations. NO production (c) and eNOS expression (d) in Pinl-knockdown cardiomyocytes treated or untreated with alcohol $(200 \mathrm{mM})$ for $24 \mathrm{~h}$. NO production (c) and eNOS expression (d) in Pinl-overexpressed cardiomyocytes treated or untreated with alcohol (50 mM) for $24 \mathrm{~h} .^{*} p<0.05$ and ${ }^{* *} p<0.01$. 


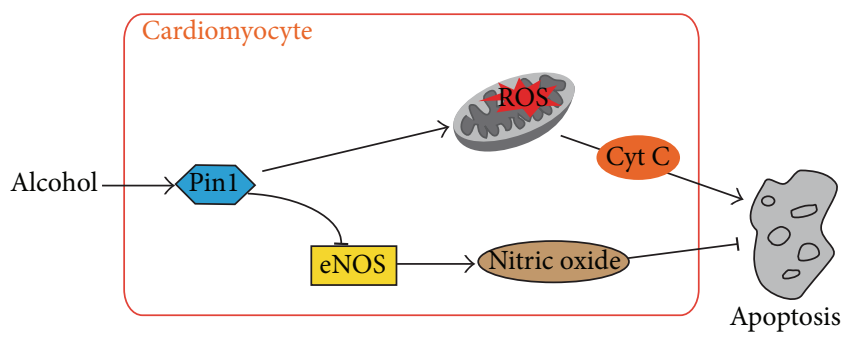

Figure 6: Schematic representation of Pinl in the process of alcoholinduced cardiomyocyte apoptosis.

Pinl in turn played a pivotal role in alcohol-induced cardiomyocyte apoptosis by promoting ROS accumulation and repressing eNOS expression (Figure 6).

ROS are free radicals containing oxygen molecules, mostly generated in mitochondria, which contain peroxyl, alkoxyl, superoxide anions, hydroxyl radicals, and oxygen derived nonradical species [27]. Depending on the concentration of ROS, it can be beneficial or harmful to cells and tissues [28]. Normal ROS metabolism plays an essential role in disease resistance and cell-mediated immunity. However, high levels of ROS may cause uncontrolled oxidation of lipids, proteins, and DNA, which finally leads to apoptosis [27]. Previous studies have suggested that high levels of alcohol can induce ROS-mediated apoptosis in cardiomyocytes [8, 11]. Since we found that alcohol treatment stimulated expression and activity of Pinl in mouse primary cardiomyocytes, we then investigated the role of Pinl in regulation of alcoholinduced ROS accumulation in mitochondria. Our results showed that depletion of Pinl significantly reduced the mCyt.C release, loss of mitochondrial membrane potential, and mROS production stimulated by alcohol treatment of cardiomyocytes, which might be mediated by $\mathrm{p} 66^{\text {shc }}$. Conversely, overexpression of Pinl even enhanced cardiomyocyte apoptosis. Interestingly, the increase of Pinl activity was not as high as the increase of Pinl expression level when we treated cardiomyocytes with high-dose alcohol, which indicates that Pinl might function by interacting with other cofactors.

We also found that Pinl promoted alcohol-induced cardiomyocyte apoptosis by inhibiting NO production. NO is a free radical, the product of the reaction catalyzed by eNOS [29]. NO levels were originally found to be closely related to inflammatory status, and NO promotes tumor cell proliferation, mobility, and invasiveness [29-31]. With regard to apoptosis, Shen et al. reported that upregulation of eNOS protects cardiomyocytes from apoptosis [25]. By investigating regulation of NO production by Pin1, we demonstrated that knockdown of Pinl rescued the decrease in eNOS expression and NO production, and ectopic overexpression of Pin1 resulted in less eNOS expression and NO production when the cells were treated with $50 \mathrm{mM}$ of alcohol. However, without alcohol treatment, we did not observe significant changes in NO production by overexpression of Pin1. We suspect that the inhibitory effect of Pinl on NO production is induced by alcohol. Therefore, the mechanisms by which alcohol regulates Pin1 expression and activity remain to be elucidated. Additionally, since NO and ROS scavenge each other, the effect of Pinl on NO production may also be affected by alcohol-induced ROS accumulation [32, 33]. Pin1 has been reported to recognize Ser-116 eNOS inhibitory phosphorylation to impair NO release. Therefore Pin1 might regulate eNOS activity and NO production by directly interacting with eNOS [34].

In conclusion, our findings demonstrate that alcohol induces Pinl expression and activation in a dose-dependent manner in mouse primary cardiomyocytes. We also found that depletion of Pinl significantly inhibited cardiomyocyte apoptosis by regulating mROS accumulation and NO production. Thus, we found that Pinl plays a pivotal role in alcohol-induced cardiomyocyte apoptosis, and Pinl is a potential therapeutic target for left ventricular dysfunction caused by excessive alcohol consumption.

\section{Conflict of Interests}

All authors declare that there is no conflict of interests regarding the publication of this paper.

\section{Authors' Contribution}

Weimin Li designed the experiments. Yuehong Wang, Zizhuo $\mathrm{Li}$, and $\mathrm{Yu}$ Zhang performed the experiments; Yuehong Wang, Wei Yang, Jiantao Sun, and Lina Shan analyzed the data; and Weimin Li and Yuehong Wang prepared the paper.

\section{Acknowledgments}

This work was supported by Programs for Science and Technology Development (GC09C408-2) of the Department of Science and Technology, Heilongjiang Province, grants from the Education Department of Heilongjiang Province (11541126), and the Health Department of Heilongjiang Province (2009-051). The authors would like to thank Professor Jinjun Zhao (Department of Cardiology, The First Affiliated Hospital of Harbin Medical University), Dr. Mingyu Shi (Department of Electrophysiology, The First Affiliated Hospital of Harbin Medical University), and all of the staff in the laboratory of the Department of Cardiology at The First Affiliated Hospital of Harbin Medical University for their assistance with this study.

\section{References}

[1] A. Urbano-Márquez and J. Fernández-Solà, "Alcohol consumption and heart failure," Journal of Cardiac Failure, vol. 11, no. 5, pp. 329-332, 2005.

[2] M. R. Piano, "Alcoholic cardiomyopathy: incidence, clinical characteristics, and pathophysiology," Chest, vol. 121, no. 5, pp. 1638-1650, 2002.

[3] L. Fauchier, D. Babuty, P. Poret et al., "Comparison of long-term outcome of alcoholic and idiopathic dilated cardiomyopathy," European Heart Journal, vol. 21, no. 4, pp. 306-314, 2000. 
[4] J. Fernández-Solà, R. Estruch, J.-M. Nicolás et al., "Comparison of alcoholic cardiomyopathy in women versus men," American Journal of Cardiology, vol. 80, no. 4, pp. 481-485, 1997.

[5] A. George and V. M. Figueredo, "Alcoholic cardiomyopathy: a review," Journal of Cardiac Failure, vol. 17, no. 10, pp. 844-849, 2011.

[6] J. Fernández-Solà, F. Fatjó, E. Sacanella et al., "Evidence of apoptosis in alcoholic cardiomyopathy," Human Pathology, vol. 37, no. 8, pp. 1100-1110, 2006.

[7] D. B. Chen, L. Wang, and P. H. Wang, "Insulin-like growth factor I retards apoptotic signaling induced by ethanol in cardiomyocytes," Life Sciences, vol. 67, no. 14, pp. 1683-1693, 2000.

[8] Z. Guan, C. Y. Lui, E. Morkin, and J. J. Bahl, "Oxidative stress and apoptosis in cardiomyocyte induced by high-dose alcohol," Journal of Cardiovascular Pharmacology, vol. 44, no. 6, pp. 696$702,2004$.

[9] J. M. Capasso, P. Li, G. Guideri, A. Malhotra, R. Cortese, and P. Anversa, "Myocardial mechanical, biochemical, and structural alterations induced by chronic ethanol ingestion in rats," Circulation Research, vol. 71, no. 2, pp. 346-356, 1992.

[10] L. Jing, C.-M. Jin, S.-S. Li et al., "Chronic alcohol intakeinduced oxidative stress and apoptosis: role of CYP2E1 and calpain-1 in alcoholic cardiomyopathy," Molecular and Cellular Biochemistry, vol. 359, no. 1-2, pp. 283-292, 2012.

[11] Y. Wang, J. Zhao, W. Yang et al., "High-dose alcohol induces reactive oxygen species-mediated apoptosis via PKCbeta/p66Shc in mouse primary cardiomyocytes," Biochemical and Biophysical Research Communications, vol. 456, no. 2, pp. 656-661, 2015.

[12] S. F. Göthel and M. A. Marahiel, "Peptidyl-prolyl cis-trans isomerases, a superfamily of ubiquitous folding catalysts," Cellular and Molecular Life Sciences, vol. 55, no. 3, pp. 423-436, 1999.

[13] K. P. Lu, G. Finn, T. H. Lee, and L. K. Nicholson, "Prolyl cis-trans isomerization as a molecular timer," Nature Chemical Biology, vol. 3, no. 10, pp. 619-629, 2007.

[14] J. Marsolier and J. B. Weitzman, "Pinl: a multi-talented peptidyl prolyl cis-trans isomerase and a promising therapeutic target for human cancers," Médecine/Sciences, vol. 30, no. 8-9, pp. 772778, 2014.

[15] A. Ryo, M. Nakamura, G. Wulf, Y.-C. Liou, and K. P. Lu, "Pin1 regulates turnover and subcellular localization of $\beta$-catenin by inhibiting its interaction with APC," Nature Cell Biology, vol. 3, no. 9, pp. 793-801, 2001.

[16] G. M. Wulf, A. Ryo, G. G. Wulf et al., "Pin1 is overexpressed in breast cancer and cooperates with Ras signaling in increasing the transcriptional activity of c-Jun towards cyclin D1," The EMBO Journal, vol. 20, no. 13, pp. 3459-3472, 2001.

[17] C.-W. Cheng, A. K. M. Chow, R. Pang, E. W. S. Fok, Y.-L. Kwong, and E. Tse, "PIN1 inhibits apoptosis in hepatocellular carcinoma through modulation of the antiapoptotic function of survivin," The American Journal of Pathology, vol. 182, no. 3, pp. 765-775, 2013.

[18] Y. Zhu, L. Qin, M. Li, D. Zhang, Y. Zhang, and N. Cheng, "Pin1 expression affects cell proliferation and apoptosis of SW620 cells in colorectal carcinoma," The Chinese-German Journal of Clinical Oncology, vol. 10, no. 2, pp. 100-104, 2011.

[19] E. Ehler, T. Moore-Morris, and S. Lange, "Isolation and culture of neonatal mouse cardiomyocytes," Journal of Visualized Experiments, no. 79, Article ID e50154, 2013.
[20] M. B. Yaffe, M. Schutkowski, M. Shen et al., "Sequencespecific and phosphorylation dependent proline isomerization: a potential mitotic regulatory mechanism," Science, vol. 278, no. 5345, pp. 1957-1960, 1997.

[21] T. Boussetta, M.-A. Gougerot-Pocidalo, G. Hayem et al., "The prolyl isomerase Pinl acts as a novel molecular switch for TNF- $\alpha$-induced priming of the NADPH oxidase in human neutrophils," Blood, vol. 116, no. 26, pp. 5795-5802, 2010.

[22] J. Chandra, I. Niemer, J. Gilbreath et al., "Proteasome inhibitors induce apoptosis in glucocorticoid-resistant chronic lymphocytic leukemic lymphocytes," Blood, vol. 92, no. 11, pp. 42204229, 1998.

[23] F. Paneni, S. Costantino, L. Castello et al., "Targeting prolylisomerase Pinl prevents mitochondrial oxidative stress and vascular dysfunction: insights in patients with diabetes," European Heart Journal, vol. 36, no. 13, pp. 817-828, 2015.

[24] H. M. Razavi, J. A. Hamilton, and Q. Feng, "Modulation of apoptosis by nitric oxide: implications in myocardial ischemia and heart failure," Pharmacology and Therapeutics, vol. 106, no. 2, pp. 147-162, 2005.

[25] M. Shen, L. Wang, G. Yang et al., "Baicalin protects the cardiomyocytes from ER stress-induced apoptosis: inhibition of CHOP through induction of endothelial nitric oxide synthase," PLoS ONE, vol. 9, no. 2, Article ID e88389, 2014.

[26] D. Burger, M. Lei, N. Geoghegan-Morphet, X. Lu, A. Xenocostas, and Q. Feng, "Erythropoietin protects cardiomyocytes from apoptosis via up-regulation of endothelial nitric oxide synthase," Cardiovascular Research, vol. 72, no. 1, pp. 51-59, 2006.

[27] L. Bergendi, L. Beneš, Z. Ďuracková, and M. Ferenčik, "Chemistry, physiology and pathology of free radicals," Life Sciences, vol. 65, no. 18-19, pp. 1865-1874, 1999.

[28] M. L. Circu and T. Y. Aw, "Reactive oxygen species, cellular redox systems, and apoptosis," Free Radical Biology and Medicine, vol. 48, no. 6, pp. 749-762, 2010.

[29] L. Ying and L. J. Hofseth, "An emerging role for endothelial nitric oxide synthase in chronic inflammation and cancer," Cancer Research, vol. 67, no. 4, pp. 1407-1410, 2007.

[30] S. Kashiwagi, Y. Izumi, T. Gohongi et al., "NO mediates mural cell recruitment and vessel morphogenesis in murine melanomas and tissue-engineered blood vessels," The Journal of Clinical Investigation, vol. 115, no. 7, pp. 1816-1827, 2005.

[31] M. Sasaki, S. Bharwani, P. Jordan et al., "Increased disease activity in eNOS-deficient mice in experimental colitis," Free Radical Biology and Medicine, vol. 35, no. 12, pp. 1679-1687, 2003.

[32] M. Wartenberg, M. Schallenberg, J. Hescheler, and H. Sauer, "Reactive oxygen species-mediated regulation of eNOS and iNOS expression in multicellular prostate tumor spheroids," International Journal of Cancer, vol. 104, no. 3, pp. 274-282, 2003.

[33] L. Marcocci, J. J. Maguire, M. T. Droy-Lefaix, and L. Packer, "The nitric oxide-scavenging properties of Ginkgo biloba extract EGb 761," Biochemical and Biophysical Research Communications, vol. 201, no. 2, pp. 748-755, 1994.

[34] L. Ruan, C. M. Torres, J. Qian et al., "Pinl Prolyl isomerase regulates endothelial nitric oxide synthase," Arteriosclerosis, Thrombosis, and Vascular Biology, vol. 31, no. 2, pp. 392-398, 2011. 


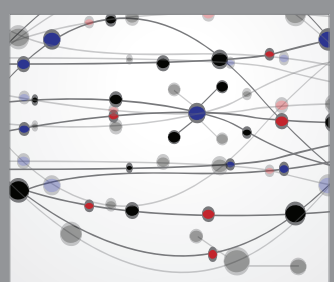

The Scientific World Journal
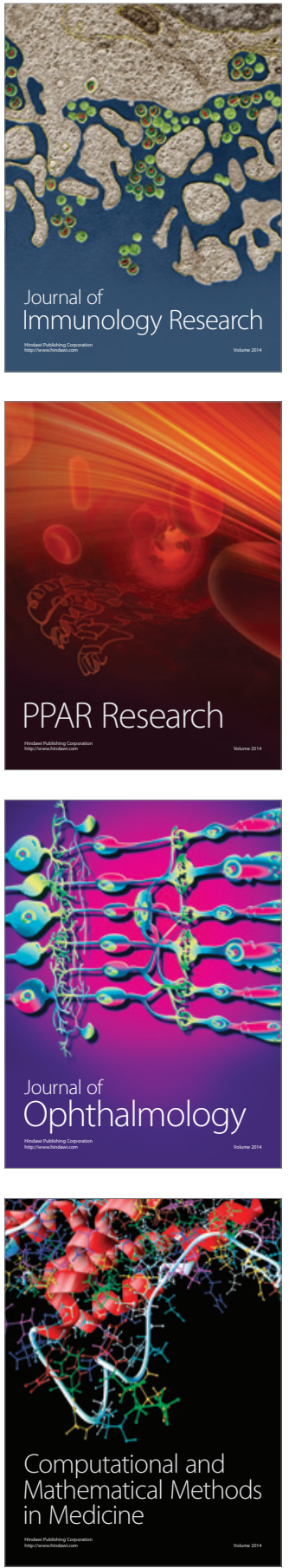

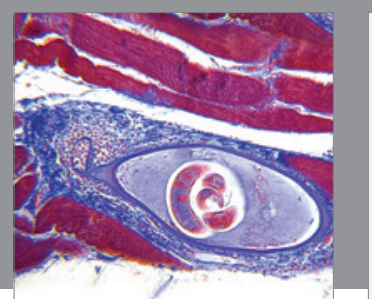

Gastroenterology Research and Practice

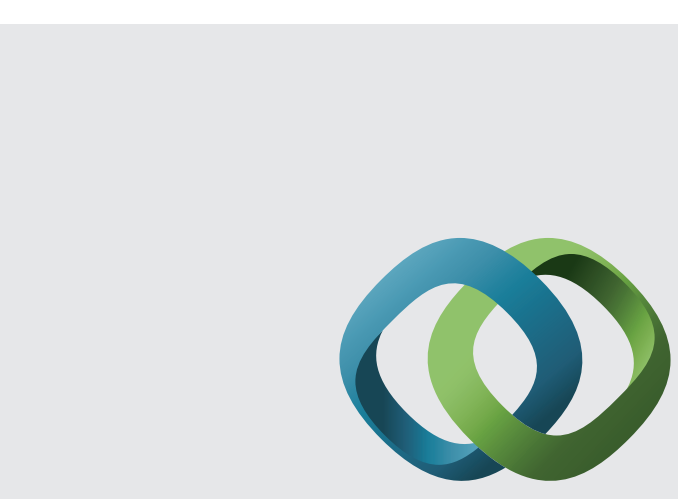

\section{Hindawi}

Submit your manuscripts at

http://www.hindawi.com
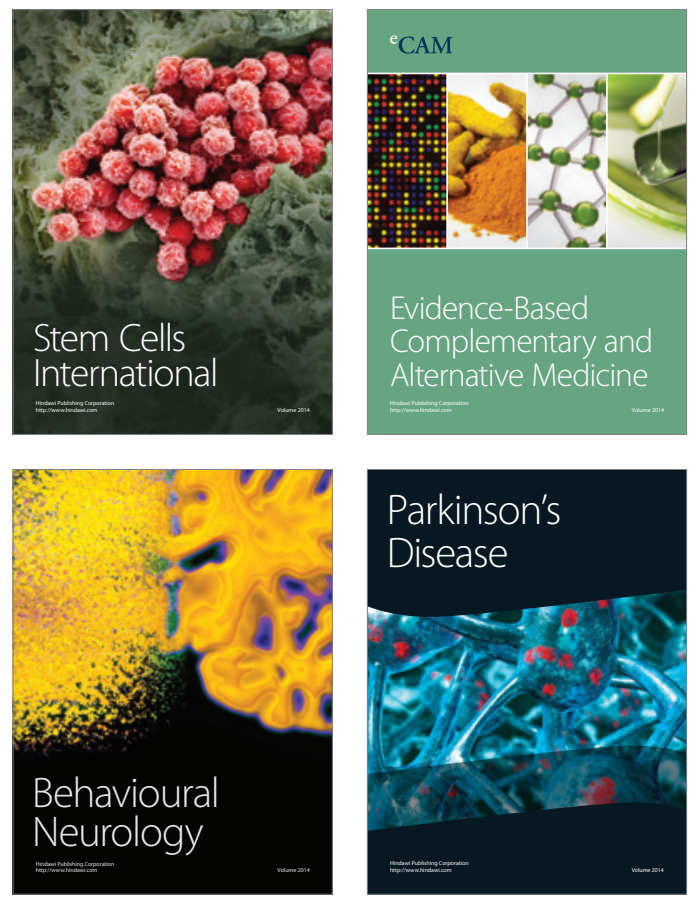
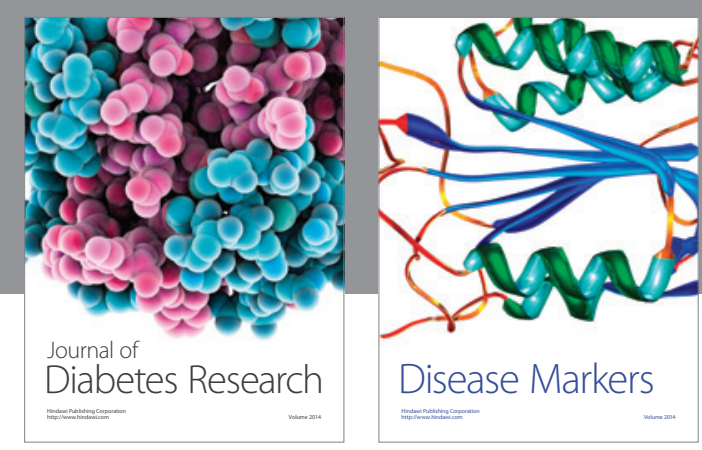

Disease Markers
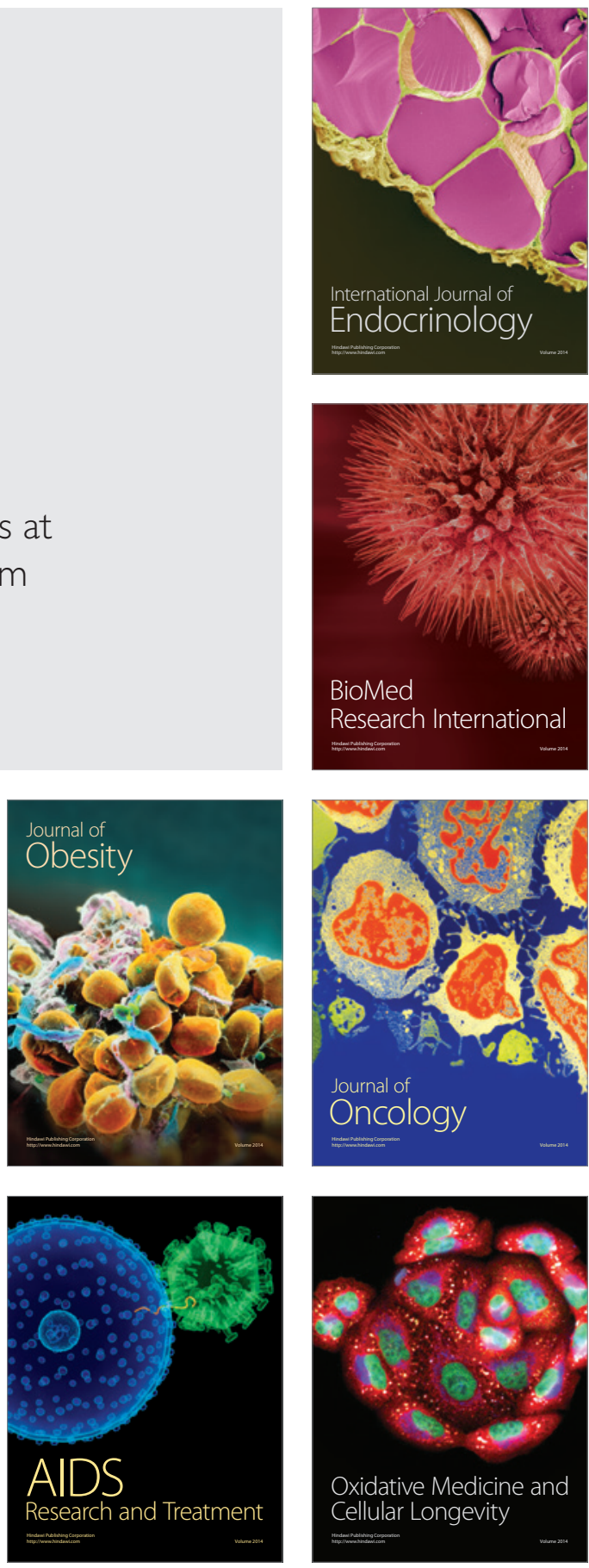